\title{
The provision of safe surgery for children
}

\author{
John D Atwell, Paul M Spargo
}

In 1977 a grant was given to the Association of Anaesthetists of Great Britain and Ireland by the Nuffield Provincial Hospitals Trust in order to carry out a confidential inquiry into deaths associated with anaesthesia. After this study a recommendation was made that future epidemiological studies should involve both anaesthetists and surgeons. The most recent report studied the deaths of children under 10 years of age within 30 days of an operation. ${ }^{1}$ Confidentiality was assured and the patients who died were subjected to an independent review by surgeons and anaesthetists. In this survey 417 deaths occurred of whom 150 were non-cardiac patients and it was possible to review in details 102 of these patients. Seventy five per cent of these patients had been admitted as an emergency.

The findings and recommendations of The National Confidential Enquiry into Perioperative Deaths (NCEPOD) ${ }^{1}$ are of vital interest to anyone responsible for the care of children. Two of the six recommendations are particularly relevant, firstly, 'Surgeons and anaesthetists should not undertake occasional paediatric practice' and secondly, 'Consultants who take the responsibility for the care of children (particularly in District General Hospitals and in single surgical specialty hospitals) must keep up to date and competent in the management of children'. No attempt was made to quantify or define the term 'occasional paediatric practice' and 'aspects of this will be discussed in this paper. It is therefore appropriate to consider the deficiencies highlighted by the report and some potential remedies.

As surgeons, anaesthetists, and paediatricians we are primarily concerned with the quality of care required for our patients. Infants and children requiring surgery should be operated upon with a minimal risk to life, few complications, and as little disturbance to the family unit as possible, that is, 'safe anaesthesia and surgery'. The British Paediatric Association is concerned about audit, which has been defined as 'the systematic critical analysis of the quality of medical care, including the procedures used for diagnosis and treatment, the use of resources and the resulting outcome for the quality of life for the patient'.

Wessex Regional Centre for Paediatric Surgery, Southampton General Hospital, Tremona Road, Southampton SO9 4XY John D Atwell Paul M Spargo Correspondence to: Mr Atwell.
There are no data comparing paediatric anaesthetic morbidity in the district general hospital with that in the regional paediatric unit. However, there are a number of large surveys of perioperative complications after anaesthesia and surgery in children (notably from the UK, France, and Canada). In the light of these studies and the infrequent exposure of most anaesthetists to children, a case can be made for the centralisation of paediatric anaesthetic (and intensive care) services.

Anaesthetic problems occur most frequently in children under 3 years of age. ${ }^{2}$ Anaesthesia in the older child is similar to that in the adult. Several large studies have confirmed the high incidence of perioperative anaesthetic complications in the neonatal and infant age ranges. In a prospective survey from France, a total of 40240 anaesthetics were administerd to children less than 15 years, 2103 (5\%) involving infants (younger than 1 year). Twenty seven major complications (defined as a fatal or life threatening accident or any incident producing severe sequelae, which occurred during, or within 24 hours of, anaesthesia) were recorded; this is an incidence of 0.7 per 1000 anaesthetics. Nine (of which four were associated with cardiac arrest) were observed in infants. The risk of complications was significantly higher $(p<0.001)$ in infants $(4.3$ per 1000$)$ than in children $(0.5$ per 1000). Of the nine events in infants, seven were respiratory problems (airway mismanagement, complications of intubation, aspiration, postoperative respiratory depression). Most of the complications seemed avoidable. ${ }^{3}$

That the younger age groups are the most vulnerable is confirmed by another study from Canada of 29220 patients under 16 years of age. Neonates had the highest rate of adverse events both intraoperatively and in the recovery room. Infants (1 month-1 year) had the next highest incidence of major perioperative events, which included respiratory and cardiovascular problems, surgical complications, and death. The intraoperative death rate in this age group was eight per 10000 and the early postoperative death rate (within three days of operation) was five per 10000 , which was the highest in any age group after the neonatal period. The authors commented that the majority of children were healthy and $70 \%$ had no preoperative medical conditions. $^{4}$

One of the recommendations of the report of NCEPOD, which looked at the causes of death in children within $\mathbf{3 0}$ days of surgery, was that surgeons and anaesthetists of adults should not undertake occasional paediatric practice, yet it has been estimated that $70 \%$ of children under 3 years are anaesthetised in adult hospitals. ${ }^{5}$ In the same editorial it was estimated that this represented one or two cases per consultant anaesthetist per week. Figures from our own 
unit confirm this: 2000 children under 3 years of age per year (and 2900 children under 5 years of age per year) mean one or two cases per consultant per week and/or one or two cases per trainee per week. In the 1989 NCEPOD report 2109 anaesthetists were asked how many children they anaesthetised each year and $80 \%$ stated that they anaesthetised less than one child in the age group 6 months to 3 years per week (40\% anaesthetised only one or two per month). Ninety per cent anaesthetised fewer than one child in the under 6 months age group per week. Even in a large district general hospital in the under 3 age group an average of only two cases are anaesthetised per consultant per month $(0.7$ cases under 1 year per consultant per month). Such small numbers are insufficient to maintain skills or allow training of junior staff $^{6}$ and they are also insufficient to allow back up staff (theatre nurses, operating department assistants, and recovery staff) to gain adequate experience. The adult intensive care of the same district general hospital admitted 25 cases under 13 years of age in the year studied (three infants and four children 1-3 years old).

Avoidance of complications is primarily a matter of training and experience. ${ }^{7}$ From the preceding discussion there is evidence that there are insufficient patient numbers to acquire and maintain paediatric anaesthetic skills. Centralisation of paediatric surgery and intensive care would improve this situation and may lead to a reduction in the distressingly high morbidity and mortality observed in the younger age ranges.

\section{Surgery}

The general surgery of childhood can be conveniently subdivided into three different age groups: (1) neonatal surgery (under 1 month of age), (2) the surgery of infancy (under 1 year of age), and (3) the surgery of the preschool child (under 5 years of age). In this paper the surgery of the older child is not considered as in some respects it is similar to that in adults. Naturally a surgical admission may be as an emergency or for an elective procedure.

There is no doubt that we are in an era of increasing specialisation within medical and surgical paediatrics. Ophthalmic and ear, nose, and throat surgery and orthopaedics are examples of 'in line specialties' whereas the 'general' paediatric surgeon specialises within an age range. In recent times subspecialty groups are increasing in numbers, such as in urology and neurological and cardiac surgeryfor example, in England and Wales there are now five surgeons who specialise in paediatric urology. As knowledge increases specialisation will gain further momentum that must be maintained if better standards of care for our patients is to be achieved.

\section{(1) THE NEONATE}

There is no doubt that the surgery of the newborn should be carried out either within regional neonatal surgical centres or within specialised units, for example, cardiac and neurosurgery.
Deficiencies have been discovered by NCEPOD $^{1}$ and these fall into two main categories. Firstly, surgeons have been operating outside their training and experience and secondly, the facilities for the full care of the neonate within some specialist units is far from ideal. This situation can be remedied by the appropriate referral of the newborn and the upgrading of facilities in some specialist units. The former is the responsibility of the referring paediatrician and the second is the responsibility of the specialist unit in conjunction with the local paediatrician. Only in this way will the overall care of the surgical neonate improve with a reduction in mortality and morbidity.

Transport of the sick neonate has always been a problem. There has been a tendency for neonatologists to refer neonates to a local surgeon rather than arrange a transfer to an appropriate neonatal or specialist unit. ${ }^{1}$

The antenatal diagnosis of a serious structural malformation such as a gastroschisis or congenital diaphragmatic hernia allows the transfer of the mother to an obstetric unit adjacent to the specialised surgical unit. Prompt surgical treatment with the minimum of disturbance to the neonate is therefore possible. This form of management has led to a reduction in the mortality of gastroschisis. ${ }^{8}$ In other conditions, particularly those affecting the genitourinary tract, the mother and baby may be transferred after delivery in their local obstetric unit. Full urological investigations of the neonate can then be undertaken in the appropriate centre.

In some instances where transfer before delivery has not occurred the receiving unit should consider the development of an emergency team which could go out and organise resuscitation and transfer of the surgical neonate. This is very appropriate for the modern management of congenital diaphragmatic hernia. Close liaison between obstetrician, neonatologist, and paediatric surgeon will ensure the optimal management of the fetus.

\section{(2) THE INFANT}

If hernias are excluded there are two emergency surgical conditions which may occur in the first year of life: congenital hypertrophic pyloric stenosis and intussusception. These operations were considered suitable for the general surgeon. This situation has changed and there is a case to be made for the transfer of such infants to a regional centre unless the local general surgeon has had training and experience as agreed by the specialist advisory committees of the Joint Higher Surgical Training Committee of the Royal College of Surgeons.

\section{(a) Congenital hypertrophic pyloric stenosis}

This procedure has a mortality and a morbidity, usually wound infection, dehiscence of the wound, and perforation of the duodenal mucosa. The incidence of some of these complications in reported series from district hospitals and specialist units is seen in the table. ${ }^{9-15}$ A study of this table will support the case for the referral of congenital pyloric stenosis to specialist units. There is a sevenfold increase in mortality 
Reported series of treated pyloric stenosis in district hospitals and specialist centres. $A$ comparison of the mortality between the two groups is significant $\left(\chi^{2}=3 \cdot 638\right.$, $p>0.05-<0 \cdot 1)$. Results are number (\%)

\begin{tabular}{|c|c|c|c|c|c|}
\hline Author & $\begin{array}{l}\text { No of } \\
\text { patients }\end{array}$ & Deaths & Perforation & $\begin{array}{l}\text { Wound } \\
\text { infection }\end{array}$ & $\begin{array}{l}\text { Wound } \\
\text { dehiscence }\end{array}$ \\
\hline $\begin{array}{l}\text { Bristol and Bolton } 1981^{9} \\
\text { Gray, et al } 1984^{10} \\
\text { McDonald } 1986^{11} \\
\text { Beynon, et al } 1987^{12} \\
\text { Erikson and Anders } 1991^{13}\end{array}$ & $\begin{array}{r}78 \\
101 \\
47 \\
100 \\
46\end{array}$ & $\begin{array}{l}\text { None } \\
2(2 \cdot 0) \\
\text { None } \\
1(1 \cdot 0) \\
\text { None }\end{array}$ & $\begin{aligned} 9(11 \cdot 5) \\
5(4 \cdot 9) \\
10(21 \cdot 2) \\
3(3 \cdot 0) \\
11(23 \cdot 9)\end{aligned}$ & $\begin{aligned} 7(9 \cdot 0) \\
11(10 \cdot 9) \\
3(6 \cdot 3) \\
14(14 \cdot 0) \\
7(15 \cdot 0)\end{aligned}$ & $\begin{array}{l}3(3 \cdot 8) \\
2(2 \cdot 0) \\
2(4 \cdot 2) \\
5(5 \cdot 0) \\
2(4 \cdot 3)\end{array}$ \\
\hline Total & 372 & $3(0.8)$ & $38(10 \cdot 2)$ & $45(12 \cdot 0)$ & $14(3 \cdot 7)$ \\
\hline $\begin{array}{l}\text { MacKay and McKellar } 1986^{14} \\
\text { Fitzgerald } 1986^{15}\end{array}$ & $\begin{array}{l}222 \\
607\end{array}$ & $\begin{array}{l}\text { None } \\
1(0 \cdot 2)\end{array}$ & $\begin{array}{l}\text { Not stated } \\
\text { Not stated }\end{array}$ & $\begin{array}{l}16 \\
\text { Not stated }\end{array}$ & $\begin{array}{l}\text { Not stated } \\
\text { Not stated }\end{array}$ \\
\hline Total & 829 & $1(0 \cdot 1)$ & & & \\
\hline
\end{tabular}

$(0 \cdot 8 \%: 0 \cdot 12 \%)$. The incidence of mucosal perforation at the operation is high $(10 \cdot 2 \%)$ with a range from $3 \%-23 \cdot 9 \%$. The reason for this is obvious when one studies in detail the findings in two of the reports. ${ }^{11} 13$ In the first study 47 patients were treated over a 10 year period by six consultants and four registrars, an average of $4 \cdot 7$ cases per year. ${ }^{11}$ In the second study of 46 patients treated over a five year period 13 were operated upon by a consultant, 19 by a senior registrar, and 14 by a registrar after fellowship, an average of two or three cases a year for the consultant, four per senior registrar, and two or three by the registrars. ${ }^{13}$ These are examples of occasional paediatric practice and so it is not surprising that the incidence of mucosal perforation was $21 \cdot 2 \%^{11}$ and $23 \cdot 9 \%^{13}$ respectively. There have been two reports with a low incidence of this complication, one by a single general surgeon with one recognised perforation out of 90 patients ${ }^{16}$ and another by a paediatrician with a single duodenal perforation out of 104 patients. ${ }^{17}$ This demonstrates the excellent results which can be achieved by the concentration of the clinical material.

\section{(b) Intussusception}

Intussusception is an uncommon surgical emergency of infancy but associated with a significant mortality. In England and Wales 33 children died of this condition between 1984 and 1989. This was an improvement over the preceding six year period when 67 children died. ${ }^{18}$ The median age of death was 7 months and was from two principal causes. Firstly, delay in diagnosis accounted for half of the deaths that occurred either at home or soon after arrival in hospital. The other causes of death were avoidable and related to inadequate intravenous fluid and antibiotic treatment, delay in recognising a recurrent intussusception, and inappropriate surgery. The sad thing is that most of these children were fit and healthy before the acute onset of an intussusception. Only one of these patients was under the care of a specialist paediatric surgeon and only then after transfer from another district hospital when the intially operating surgeon had failed in his assessment of the viability of the intestine which resulted in ischaemia, intestinal perforation, and a multisystem organ failure. Any paediatrician undertaking the correct management of intussusception by hydrostatic reduction needs to ensure that the radiologist has sufficient paediatric training and that surgical expertise exists for the $20 \%$ who may require it.

\section{(3) THE PRESCHOOL CHILD}

The commonest causes of an admission to hospital under 5 years of age are inguinal hernia, undescended testes, abdominal pain, and head injuries or other trauma. Some of these conditions such as inguinal hernia and undescended testes can be treated as an elective day case admission. Others may present as a surgical emergency (inguinal hernia, acute appendicitis) with an increased risk to the child.

\section{(a) Inguinal hernia}

The incidence of inguinal hernia varies between $2-4 \%$ in the full term infant but increased to $30 \%$ in the premature infant under $1000 \mathrm{~g}$ birth weight. Incarceration is a complication with the highest incidence in the first three months of life. It therefore follows that surgical repair of the hernia should be undertaken as soon as possible after its diagnosis. In a series of 511 infants under 1 year of age, 158 had become incarcerated but only seven required an emergency operation; the remainder reduced after sedation and postural reduction. ${ }^{19}$ In two the testes were undescended and on follow up only two patients had evidence of testicular atrophy, an incidence of $0.4 \%$. This is an example of the high standards obtainable in a specialist centre. In the NCEPOD report five infants died from complications related to surgery and anaesthesia after treatment of an inguinal hernia.

\section{(b) Undescended testes}

An undescended testis only warrants an emergency operation if complications occur such as torsion or incarceration of an associated inguinal hernia. These are relatively rare complications, thus the majority of patients are treated as elective day case admissions. It has been recommended that surgery should be undertaken before 2 years of age if an improvement in fertility is the aim of treatment. ${ }^{20}$ Orchidopexy in boys under 3 years of age requires considerable surgical expertise if complications such as damage to the vas deferens, failure to place the testis in a satisfactory position in the scrotum, and atrophy of the testis are to be avoided. Few reports appear in the literature of the morbidity of an orchidopexy, ${ }^{21}{ }^{22}$ but in one series of 142 orchidopexies atrophy was found in $31 \%$ and an unsatisfactory result in $35 \%$ when reviewed five years after surgery. ${ }^{21}$ In a similar review from the same centre nine years later and after the appointment of a general surgeon with interest, training, and experience in paediatric surgery the incidence of atrophy was $9 \cdot 4 \%$ of 128 orchidopexies. This single example highlights the importance of appropriate training and experience in performing a routine standard, and in the past a general surgical operation.

\section{(c) Acute appendicitis and abdominal pain}

Acute appendicitis is fairly uncommon in the child under 5 years old. In older children the 
acute abdomen is a common cause for an emergency hospital admission of whom approximately $50 \%$ will need a laparotomy. ${ }^{23}$ Acute appendicitis has a mortality particularly in the very young. Two hundred and four children died from acute appendicitis from $1963-7,{ }^{24}$ and the mortality was eight times higher in those aged less than 5 years of age compared with those aged 5-14 years.

\section{NCEPOD}

The first conclusion of the inquiry was that 'The prudence of the occasional surgeon undertaking complex childhood surgery must be questioned'. However, five deaths occurred in infants with a strangulated hernia and in the eyes of a general surgeon and possibly a paediatrician this is not a complex procedure.

A second purpose or result of the inquiry was to determine the number of children operated upon by 5000 consultant surgeons in each year. The children were subdivided into three groups aged 0-6 months, 6 months -3 years, and 3-10 years. Only $39 \%$ of surgeons operated on more than $\mathbf{4 0}$ children per year under 10 years of age, that is, less than one per week.

Considering general surgeons in greater detail it was found that $12 \%$ never operated upon children, another $19 \%$ did not operate on children under 6 months of age, and another $32 \%$ operate on infants under 6 months of age but less than 10 patients per year. The only conclusion that can safely be drawn from this data is that ' $A$ rethink is necessary for the provision of general surgical services to children'.

Finally considering the care of children within special surgical units (for example, neurosurgery, burns, cardiothoracic and plastic surgery) it was found that these infants and children were often 'denied the care of paediatricians and specialist paediatric nurses'. Similarly it was also reported that general surgeons were occasionally pressurised by enthusiastic neonatologists to operate upon patients outside their usual expertise rather than transfer them.

\section{The future}

From the data that has been presented and from the NCEPOD report it seems that changes are needed in the present system of management of surgical problems in the infant and young child. In Australia and the USA paediatric surgery is only undertaken by paediatric surgeons at all ages and the standard of care is very high. In this country the standard of care is high ${ }^{1}$ but that does not mean that improvements are not possible. For example we have shown that there has been a considerable improvement in the mortality of intussusception in recent years. ${ }^{18}$

In the past incarcerated hernia, pyloric stenosis, and intussusception were considered general surgical operations that any surgeon could do. This must now be questioned. In addition to the data presented, it is also important to appreciate that many surgical trainees receive little exposure to the surgical care of infants and young children and the number of adult general surgeons able to operate on infants will therefore decrease.

One solution to this situation is that all the general surgery of the very young, that is, on those under 3 years of age, should be referred to specialist centres especially if the admission is an emergency rather than for an elective procedure. In most of these centres there will either be paediatric surgical and paediatric anaesthetic expertise available. The British Association of Paediatric Surgeons has suggested that transfer of patients under 5 years should be the eventual aim. In our own unit $60 \%$ of day case admissions for an elective general surgical procedure are under 5 years of age.

If this method of management is undertaken one has to determine whether the existing paediatric surgical units could cope with the increased work load. Taking pyloric stenosis as an example of an emergency with a 2 million population, the expected annual work load could be 100 patients, that is two patients per week. The figures for intussusception are about half this. The duration of hospital stay is now short (two or three days), thus this commitment would require at leat 300 bed days per year.

The vast majority of the elective surgery in the very young can safely be performed on a day basis, for example, inguinal herniotomies, orchidopexies, and circumcisions, especially with good back up in the community by paediatric trained district nurses. ${ }^{25} 26$ A children's day surgical unit of six beds has the capacity to treat 50-60 patients per week, that is, up to 2000 a year. In our own children's day unit in Southampton $52 \%$ of admissions come from Southampton and its immediate environs and $48 \%$ are from further afield within the Wessex region. In fact with the efficient use of day beds our overall patient turnover has increased $330 \%$ since 1966 to 1969.

The NCEPOD report highlighted the risks and dangers of the 'occasional surgeon' but did not attempt to define the limits of such experience. This has been discussed under pyloric stenosis and intussusception. It depends upon the views about the value in concentrating experience. ${ }^{27-29}$ In Liverpool when neonatal surgery was concentrated into a single unit the mortality fell from $75 \%$ to $25 \%$ within five years. A similar concentration for the general surgery of the child under 3 years of age should result in an improvement in mortality and morbidity.

Improvements in patient care can be achieved by improving facilities, for example paediatric surgical centres should have inpatient beds, day care beds, and five day stay beds. These facilities combined with paediatric community care would increase efficiency and patient turnover.

There is no doubt that audit of surgical results will eventually lead to an overall improvement in the care of the patient but surgical customs and prejudices will need to be overcome. We are in an era of increasing specialisation within medicine and surgery. On a personal basis one is competent to perform abdominoperineal resections of the rectum or prostatectomy in adults but one very much 
doubts whether the results would approach those achieved by a practicing colorectal surgeon or urologist. Our surgical aims must remain in trying to improve the standards of care which our young children need and deserve.

1 Campling EA, Devlin HB, Lunn JN. Report of the national confidential enquiry into perioperative deaths 1989. London: 1990 .

2 Anonymous. Paediatric anaesthesia [Editorial]. BMF 1978;ii: 717.

3 Tiret L, Nicoche Y, Hatton F, Desmonts JM, Yourc HG Complications related to anaesthesia in infants and children. Br ₹ Anaesth 1988;61:263-9.

4 Cohen NM, Cameron CB, Duncan PG. Pediatric anaesthesia morbidity and mortality in the perioperative period. Anaesthesia and Analgesia 1990;70:160-7.

5 Hatch DJ. Anaesthesia for children [Editorial]. Anaesthesia 1984;39:405-6.

6 Bowham AR, Morgan-Hughes JO. Forum: paediatric anaesthesia in a district general hospital. Anaesthesia 1989;44:139-42.

7 Anonymous. Complications of anaesthesia in infants and children [Editorial]. Lancet 1988;ii:1466.

8 Stringer MD, Brereton RJ, Wright VM. Controversies in the management of gastroschisis: a study in $\mathbf{4 0}$ patients. Arch Dis Child 1991;66:34-6.

9 Bristol JB, Bolton RA. The results of Ramstedt's operation in a district hospital. Br $\mathcal{J}$ Surg 1981;68:590-2.

10 Gray DW, Gear M, Stevens DW. The results of Ramstedt's operation: room for complacency? Annals of the Royal College of Surgeons of England 1984;66:280-2.

11 McDonald PJ. Ramstedt's operation in district hospitals-is it safe? $\mathcal{F} R$ Soc Med 1986;79:17-8.

12 Beynon J, Brown R, James C, Fernando R. Pyrloromyotomy: can the morbidity be improved? $\mathcal{f} R$ Coll Surg Edinb 1987;32:291-2.
13 Eriksen CA, Anders CJ. Audit results of operations for infantile pyloric stenosis in a district general hospital. Arch Dis Child 1991;66:130-3.

14 MacKay AJ, Mackellar A. Infantile hypertrophic pyloric stenosis: a review of 222 cases. Aust NZf Surg 1986;56: 131-3.

15 Fitzgerald $\mathrm{R}$. Infantile hypertrophic pyloric stenosis. Ir Med $\mathcal{F}$ 1986;79:112-3.

16 Shucksmith HS. Congenital pyloric stenosis. University of Leeds Medical Magazine 1950;20:1-2.

17 Jacoby NM. Pyloric stenosis: selective medical and surgical treatment. A survery of 16 years experience. Lancet treatment. A

18 Stringer MD, Pledger G, Drake D. Childhood deaths from intussusception in England and Wales 1984-1989. BMF (in press).

19 Puri P, Guiney EJ, O'Donnell B. Inguinal hernia in infants: the fate of the testis following incarceration. $\mathcal{F}$ Pediatr Surg 1984;19:44-6.

20 Hedinger CHR. Histological data in cryptorchism: cryptorchism, diagnosis and treatment. Pediatric Adolescence and Endocrinology 1979;6:3-13.

21 Evans JP, Rutherford JH, Bagshaw PF. Orchidopexy in prepubertal boys. Five year survey. Urology 1978;12: 509-13.

22 London NJM, Joseph HT, Johnstone JMS. Orchidopexy: the effects of changing patterns of referral on outcome. $\mathrm{BrF}$ Surg 1987;74:636-8.

23 Winsey HS Jones PF. Acute abdominal in childhood: analysis of a year's admissions. BMF 1967;i:653-5.

24 Pledger HG, Buchan R. Deaths in children with acute Pledger HG, Buchan R. Deaths in
appendicitis. BMf 1969;ii:466-70.

25 Gow MA, Atwell JD. The role of the children's nurse in the community. F Pediatr Surg 1980;15:26-30.

26 Atwell JD, Gow MA. Paediatric trained district nurse in the community: expensive luxury or economic necessity. $B M \mathcal{F}$ 1985; ii:227-9.

27 Jones PF. The general surgeon who cares for children. BMF 1986;ii:1156-8.

28 Gough $M H$. Perioperative deaths among children. $B M \mathcal{F}$ 1990;300:1606.

29 Anonymous. NCEPOD and perioperative deaths of children. [Editorial]. Lancet 1990;335:1498-500. 